\title{
Effect of pterygium severity on visual acuity and contrast sensitivity
}

\author{
Vohra M. ${ }^{1}$, Agarwal R. ${ }^{2}$, Vohra J. ${ }^{3}$, Maggoo A. ${ }^{4}$, Rohatgi S. ${ }^{5}$ \\ ${ }^{1}$ Dr. Malini Vohra, Assistant Professor, ${ }^{2}$ Dr. Ruchika Agarwal, Associate Professor; ${ }^{3}$ Dr. Jaya Vohra, Senior Resident, \\ Government Medical College Ratlam, M P. ${ }^{4}$ Dr. Ashish Maggoo, Kanpur, U.P, ${ }^{5}$ Dr. Sanjeev Rohatgi, Professor, \\ 1,2,5 authors are affiliated with Rama Medical College and Research Centre, Mandhna, Kanpur, U.P. India.
}

Corresponding Author: Dr. Ruchika Agarwal, 7/57, Ratan Enclave, Tilak Nagar, Kanpur, Uttar Pradesh, India. E-mail: ruchidrjain@yahoo.co.in

\begin{abstract}
Aim: To evaluate prospectively the effect of pterygium excision on visual acuity and contrast sensitivity before and after surgery. Material \& method: A prospective observational study where in 63 eyes of 63 patients with primary pterygia were studied before and after surgery. Examination was done in which contrast sensitivity was measured with pellirobson chart pre-operatively and one month postoperatively following pterygium excision with Conjunctival Limbal Auto Graft. Result: As the grade of pterygium increases, decrement in contrast sensitivity occurs. The visual acuity significantly increased after the surgery. Mean contrast sensitivity following pterygium surgery improved from $1.49 \pm 0.21$ to $1.70 \pm 0.20$ ( $\mathrm{p}$ value $<0.001$ ). Conclusion: Visual acuity and contrast sensitivity improved significantly following pterygium excision surgery.
\end{abstract}

Key words: pterygium, conjunctiva, fibrous connective

\section{Introduction}

The pterygium is classically defined as a degenerative disease of the ocular surface with triangular fibrovascular tissue formation, which grows from the conjunctivatowards the surface of the cornea [1]. Although histopathogenesis has not been fully elucidated; it is very likely that the pterygium represents a degenerative response of the fibrous connective tissue to different stimuli. Among the risk factors, exposure to ultra violet radiation appears to play an important role in inducing damage to the limbal stem cells. As a result, there is a migration of the conjunctiva towards the cornea, chronic inflammation and fibrovascular tissue formation [2]. Other risk factors described related to the development of pterygium are the micro-traumas in the corneal limbus region and hereditary factors.

The main risk factor is exposure to ultraviolet rays, and a possible explanation of this fact would be the location of pterygium, mainly in the interpalpebral fissure, which is more exposed to sun raysand dust, leading to inflammation of the ocular surface. Recently, it was suggested that there is a mutation in thep 53 gene on chromosome 17 as the cause of this disease, and

Manuscript received: $14^{\text {th }}$ February 2019

Reviewed: $24^{\text {th }}$ February 2019

Author Corrected: $4^{\text {th }}$ March 2019

Accepted for Publication: $7^{\text {th }}$ March 2019 changes in the expression of various growth factors, such as vascular endothelial growth factor A (VEGFA). Histologically, the pterygium is characterized by elastoticde generation of the conjunctival substantia propria, with eosinophilic and basophilic deposits and fibroblast proliferation [1]. Large pterygia occluding the visual axis decrease visual acuity. However, even before entering theoptical zone, an advancing pterygium can cause visual impairment by locally flattening the cornea and inducing with-the-rule astigmatism and decreasing contrast sensitivity. Previous reports have demonstrated that the topographic changes in the cornea and visual impairment induced by pterygia can be reversed following removal [3]. Contrast sensitivity is reported to be involved in visual performance in daily life and in indoor activities such as face recognition[4,5].

The contrast sensitivity function has proved auseful tool for detecting visual disturbances when Snellen acuity failstoshow comparabledys function for in pterygia. Pterygium causes reduction in contrast sensitivity. Both spatial contrast sensitivity and glare disability are worsened in patients with pterygia even when the Snellen visual acuity is minimally affected. The decline of contrast sensitivity in eyes with pterygium and 
relatively good vision on Snellen's optotypes is the cause of some subjective complaints of the patients and may be an important factor in indication of pterygium surgery ofeyes with a relatively good visual acuity. We performed this study in order to investigate the effect of pterygium surgery contrast sensitivity and visual acuity.

\section{Materials and Methods}

Type of study: Prospective interventional case study wasconducted.

Place of study: Cornea Clinic of Department of Ophthalmology, Rama Medical College and Research

Centre Mandhna, Kanpur. The study included 63 patientsattending the OPD and Cornea Clinic of the Departmentof Ophthalmology, Rama Medical College and Research Centre Mandhna, Kanpur.

Inclusion criteria: Patients with primary pterygium with $\geq 2 \mathrm{D}$ astigmatism were included in study.

Exclusion criteria: Pterygium with any anterior orposterior segment pathology was excluded from study.

Statistical method: re-operative and postoperative valueswere compared using paired t-test. Contrast sensitivity was compared against the grade of pterygium usingANOVA test.

Surgical Procedure: All surgeries were performed under peribulbar anesthesia. A small conjunctival incision was made medial to head of pterygium and sub conjunctival dissection carried out up to caruncle, superior and inferior fornix. The corneal epithelium $2 \mathrm{~mm}$ anterior of head was scrapped off with blade no. 11 Bard Parker blade and the pterygium head avulsed using a combination of blunt dissection and traction. The body of pterygium was then excised.

Hemostasis was achieved by applying light cautery to bleeders. After the pterygium mass was removed, a limbalconjunctival auto graft was procured from the superior conjunctiva; the graft dissection was extended approximately $0.5 \mathrm{~mm}$ into clear cornea to include the Vogt palisades and limbal stem cells. This graft was moved to cover the defective area and was secured with 10-0 nylon sutures. The limbal end of the autograft was placed directly over the limbal area of the surgical bed. The sutures were removed under the operating microscope after conjunctival epithelialization occurred.

Examination included: Snellen visual acuity, slit lamp examination, manual keratometry, contrast sensitivity with pellirobson chart was done pre-operatively and one month post operatively. Nasal pterygium was graded depending on the extent of corneal involvement.

Grade I - Pterygium crossing limbus $<2 \mathrm{~mm}$ ontocornea.

Grade II - Pterygium crossing limbus onto $\geq 2-4 \mathrm{~mm}$ ofcornea

Grade III - Pterygium crossing limbus onto $>4 \mathrm{~mm}$ ofcornea and reaching up to pupillary margin

Grade IV- Pterygium crossing pupillary margin.

Contrast Sensitivity Examination: Contrast sensitivity was recorded using Pelli- Robson chart. Method of recording contrast sensitivity with Pelli- Robson chart: Subject was seated directly in front of Pelli-Robson chart at a distance of 1 meter with the best distance correction. Subject is asked to outline each letter on the chart. Test is concluded when the subject guesses two of the three letters of the triplet incorrectly. Subject's sensitivity is indicated by the finest triplet for which two of the three letters are named correctly.

Table No.-1: Grade wise distribution of cases/eyes.

\begin{tabular}{|c|c|}
\hline Grade of pterygium & Number of patient \\
\hline Grade I & 8 \\
\hline Grade II & 27 \\
\hline Grade III & 25 \\
\hline Grade IV & 30 \\
\hline Total & 63 \\
\hline
\end{tabular}

Table 1 shows grade wise distribution of cases. In present study, 8 eyes had grade I pterygium, 27 eyes had grade II pterygium, 25 eyes had grade III pterygium and 3 eyes had grade IV. 
Original Research Article

Table No.-2: Comparison of grade wise pre-op and post op contrast sensitivity (CS)

\begin{tabular}{|c|c|c|c|}
\hline Grade of pterygium & Pre-Op Mean C S & Post-Op Mean CS & P value \\
\hline Grade I & $1.69 \pm 0.20$ & $1.89 \pm 0.20$ & 0.22 \\
\hline Grade II & $1.51 \pm 0.13 \mathrm{t}$ & $1.74 \pm 0.14$ & $<0.001$ \\
\hline Grade III & $1.45 \mathrm{D} \pm 0.19$ & $1.64 \pm 0.16$ & $<0.001$ \\
\hline Grade IV & $1.25 \pm 0.10$ & $1.45 \pm 0.10$ & $<0.001$ \\
\hline Mean & $1.49 \pm 0.21$ to & $1.70 \pm 0.20$ & $<0.001$ \\
\hline
\end{tabular}

The above table shows that pterygium excision surgery cause improvement in contrast sensitivity in all grades of pterygium. The improvement was significant in grade II,III,IV having p value $(<0.001)$ and not significant in grade I $p$ value $(0.225)$.

Table No.-3: Comparison of pre-op and post op BCVA.

\begin{tabular}{|c|c|c|c|}
\hline Grade of pterygium & Pre-Op Mean BCVA & Post-Op Mean BCVA & P value \\
\hline Grade I & $0.85+/ 0.17$ & $0.95+/ \_0.10$ & 0.184 \\
\hline Grade II & $0.58+/ 0.22$ & $0.79+/ \_0.21$ & $<0.001$ \\
\hline Grade III & $0.41+/ 0.14$ & $0.56+/ \_0.14$ & $<0.001$ \\
\hline Grade IV & $0.08+/ 0.02$ & $0.18+/[0.07$ & $<0.001$ \\
\hline
\end{tabular}

The above table shows improvement of BCVA in all grades of pterygium following pterygium excision surgery. The improvement was significant in grade II,III,IV p value $(<0.001)$ and not significant in grade I p value $(0.184)$.

\section{Discussion}

A pterygium-induced refractive change often leads tovisual impairment. Pterygium leads to inflammation, foreign body sensation, tearing, dry and itchy eye. The indications for pterygium surgery are cosmetic disfigurement, visual impairment, recurrent inflammation and motility restriction. Surgical intervention resulted inan increase in the mean refractive power at one monthafter surgery, which indicates a steepening of flattened cornea. Pterygium induced astigmatism appears to be dueto alteration in tear film caused by lesion.

As the head of pterygium approaches the apex of cornea, a tear meniscus develops between the corneal apex and the elevated pterygium, causing an apparent flattening of normal corneal curvature [6,7]. Previous studies have shown thatpterygium cause corneal distortion which induce a significant amount of astigmatism $[8,9,10,11]$.

The exact mechanism of flattening in horizontal meridian due to pterygium is not clear. It is thought to be caused by the formation of tear meniscus between the corneal apex $[6,12]$ and the elevated pterygium, causing an apparent flattening of the normal corneal curvature [13]. As this flattening is along the horizontal meridian, it usually causes with-the-rule corneal astigmatism. Pterygium excision induces a reversal of pterygium related corneal flattening [6,14]. Comparison of pre and post operative corneal topography also revealed significant changes in the majority of to pographic parameters. Numerous studies have documented improvement in the corneal condition and topographic indices after pterygium excision $[15,16,17]$.

Unlike Yasar et al [12] who considered no role for fibrovascular traction in pterygium induced corneal changes, Oldenburg et al[6] and Budak et al[18] hypothesized that flattening of the cornea and changes in the corneal topography may be produced by a pooling oftears at the apex of the pterygium or by its mechanical traction.

These abnormalities and their effects on thecornea are mostly reversible by the surgery especially inthe cases of early intervention [17,15,24,21]. Previous studies have reported the association of pterygium and contrast sensitivity. Lin et al in 1989 showed that contrast sensitivity was lower at all spatial frequencies in the patients with pterygium.

Another study showed that contrast sensitivity at medium to-high spatial frequenciesof 6,12 , and $18 \mathrm{cpd}$ significantly improved after pterygium excision, while contrast sensitivity at low spatial frequencies of 1.5 and $3 \mathrm{cpd}$ did not change after surgery [20]. 
A Maliket al [21] found a significant negative correlation was seen between contrast sensitivity and the vertical, horizontal dimensions and the area of the pterygium. Maximum correlation was seen with the vertical dimension of pterygium, followed by area andthen horizontal width. In present study it was observed that contrast sensitivity decreases with increase in gradeof pterygium. Contrast sensitivity reduced maximally ingrade IV and minimally in grade I. There was statistically significant correlation between grade of pterygium and, contrast sensitivity (pvalue $<0.001$ ).

Our findings are in accordance with the findings of another workers Lin et al in1989 [22]. Pterygium can cause an asymmetric distortion ofthe cornea, because the lesion typically extends radially from the corneal periphery. The disruption to the corneal surface to pography induces both coma and trefoil wave front errors (WFEs) $[23,24]$. There is commonly an increase incorneal and refractive astigmatism with pterygium as well as an increase in Higher-order wave front error (HOWFE), with an effect proportional to the extent of thelesion $[25,26]$. Because the condition approaches lateral to thevisual axis, a change in Surface Asymmetry Index (SAI) is not usually a feature of the condition. Higher-order wave front error is associated with corresponding reduction in visual acuity and contrast sensitivity [27].

Studies indicate that contrast sensitivity testing may provide additional objective methods for documenting impaired vision in patients with pterygium when Snellen visual acuity is minimally affected [28]. Corneal astigmatism and contrast sensitivity values inpatients with pterygia are useful indicators for the needof pterygium surgery or as indicators of surgical success [29]. In the present study, 8 eyes had grade 1pterygium, 27 eyes had grade 2 pterygium, 25 eyes had grade 3pterygium and 3 eyes had grade 4 pterygium. Our findings are in accordance with the findings of other workers [30]. The preoperative mean astigmatism was $3.29 \mathrm{D} \pm 1.46$.

The astigmatism decreased significantly following pterygium excision. The mean preoperative refractive cylinder decreased from $3.29 \mathrm{D} \pm 1.46 \mathrm{D}$ to $1.49 \pm 0.82 \mathrm{D}$ post operatively $(p<0.001)$. Pterygium induced impaired visual acuity may be caused by analteration in tear film or by mechanical effects of the lesion. Therefore, excision of the lesion may lead to reconstruction of the normal surface, and thus, improvement in the visual acuity [26]. Statistically improvement in BCVA in grade II, grade III and grade IVpterygium was due to reduction of astigmatism. Linet.al.in 1989 found that contrast sensitivity was lower atall spatial frequencies in the patients with pterygium. Another study observed that contrast sensitivity at mediumto-high spatial frequencies of 6,12 , and $18 \mathrm{cpd}$ significantly improved after pterygium excision, while contrast sensitivity at low spatial frequencies of 1.5 and $3 \mathrm{cpd}$ did not change after surgery [30]. In present study it was observed that contrast sensitivity decreases with increasein grade of pterygium. Contrast sensitivity reduced maximally in grade IV and minimally in grade I.

There was statistically significant correlation between grade of pterygium and contrast sensitivity. Our findings are in accordance with the findings of Lin et al in 1989. The contrast sensitivity improved significantly following pterygium excision. The mean preoperative contrasts ensitivity increased from $1.49 \pm 0.21$ to $1.70 \pm 0.20$ post operatively. Surgical removal of pterygium caused asignificant improvement in contrast sensitivity. The mean preoperative contrast sensitivity improved from $1.69 \pm 0.20$ to $1.83 \pm 0.20$ post operatively $(\mathrm{p}=0.22)$ in grade Ipterygium, from $1.51 \pm 0.13$ to $1.74 \pm 0.14$ was noticed in grade II. In grade III pterygium contrast sensitivity increased and in grade IV contrast sensitivity increased from $1.25 \pm 0.10$ to $1.45 \pm 0.10$. The amount of contrast sensitivity increased significantly following pterygium excision ingrade II, grade III and grade IV but in grade I, the increase in the amount of contrast sensitivity after pterygium excision was not statistically significant (pvalue 0.22).

\section{Conclusions}

Surgical excision of pterygium improves contrast sensitivity, visual acuity and reduce astigmatism. Contrast sensitivity is reported to be involved in visual performance in daily life and in indoor activities such as face recognition. The contrast sensitivity function has proved auseful tool for detecting visual disturbances when Snellen acuity failstoshow comparabledys function for in pterygia.

Contrast sensitivity testing may provide additional objective methods for documenting impaired vision in patients with pterygium when Snellen visual acuity is minimally affected. Corneal astigmatism and contrast sensitivity values in patients with pterygia are useful indicators for the need of pterygium surgery or as indicators of surgical success. The study demonstrates usefulness of visual acuity and contrast sensitivity tests and how they can be incorporated into the decision as to when to do pterygium excision surgery. The decline of 
contrast sensitivity in eyes with pterygium and relatively good vision on Snellen's optotypes is the cause of some subjective complaints of the patients and may be animportant factor in indication of pterygium surgery ofeyes with a relatively good visual acuity.

\section{Current study Added to the existing Knowledge:} Contrast sensitivity testing may provide additional objective methods for documenting impaired vision inpatients with pterygium when Snellen visual acuity is minimally affected.

The study demonstrates usefulness of visual acuity and contrast sensitivity tests and how they can be incorporated into the decision as to when to do pterygium excision surgery.

\section{Contribution from Various authors}

- Dr. MaliniVohra -Designing of study and manuscript preparation.

- Dr. Ruchika Agarwal - Maintenance of data and follow up of patients.

- Dr. Jaya Vohra -Statistical analysis and collection of references.

- Dr Ashish Maggoo- Reference of patients.

- Dr. Sanjeev Rohatgi- Critical analysis of the whole study

\section{Funding: Nil, Conflict of interest: Nil Permission from IRB: Yes}

\section{References}

1. Bazzazi N, Ramezani A, Rabiee MAS. A comparative study of conjunctival autograft and minimally invasive pterygium surgery in primary pterygia. Pak J Biolog Sci. 2010;13(8):409-412.

2. Akinci A, Zilelioglu O. Comparison of limbalconjunctival autograft and intraoperative $0.02 \%$ mitomycin-C for treatment of primary pterygium. Int Ophthalmol. 2007 Oct;27(5):281-5. Epub 2007 Aug 8.

3. Ozdemir M, Cinal A. Early and late effects of pterygium surgery on corneal topography. Ophthalmic Surg Lasers Imaging. 2005 Nov-Dec;36(6):451-6.

4. Montés-Micó R, Charman WN. Choice of spatial frequency for contrast sensitivity evaluation after corneal refractive surgery. J Refract Surg. 2001 NovDec; 17(6):646-51.
5. Ojanpää $H$, Näsänen R. Utilisation of spatial frequency information in face search. Vision Res. 2003 Nov;43(24):2505-15

6. Oldenburg JB, Garbus J, McDonnell JM, et al. Conjunctival pterygia. Mechanism of corneal topographic changes. Cornea. 1990 Jul;9(3):200-4.

7. Maheshwari S. Effect of pterygium excision on pterygium induced astigmatism. Indian $\mathrm{J}$ Ophthalmol. 2003 Jun; 51 (2): 187-8.

8. Tomidokoro A, Miyata K, Sakaguchi Y, et al. Effects of pterygium on corneal spherical power and astigmatism. Ophthalmology. 2000 Aug;107(8):1568-71.

9. Lindsay RG, Sullivan L. Pterygium-induced corneal astigmatism. Clin Exp Optom. 2001 Jul;84(4):200-203.

10. Bahar I, Loya N, Weinberger D, et al. Effect of pterygium surgery on corneal topography: a prospective study. Cornea. 2004 Mar;23(2):113-7.

11. Yilmaz S, Yuksel T, Maden A. Corneal topographic changes after four types of pterygium surgery. J Refract Surg. 2008 Feb;24(2):160-5. doi: 10.3928/1081597X20080201-06.

12. Cinal A, Yasar T, Demirok A, et al. The effect of pterygium surgery on corneal topography. Ophthalmic Surg Lasers. 2001 Jan-Feb;32(1):35-40.

13. Hong JW, Lee TS. Comparison of Refractive Change Measured by corneal topography before and after pterygium excision. J Korean opthalmol Soc. 1996 Oct (10):1614-1689.

14. Fong KS, Balakrishnan V, Chee SP, et al. Refractive change following pterygium surgery. CLAO J. 1998 Apr; 24 (2): 115-7.

15. Yagmur M, Ozcan AA, Sari S, et al. Visual acuity and corneal topographic changes related with pterygium surgery. J Refract Surg. 2005 Mar-Apr;21(2):166-70.

16. Yilmaz S, Yuksel T, Maden A. Corneal topographic changes after four types of pterygium surgery. J Refract Surg. 2008 Feb;24(2):160-5. doi: 10.3928/1081597X20080201-06.

17. Stern GA, Lin A. Effect of pterygium excision on induced corneal topographic abnormalities. Cornea. 998 Jan;17(1):23-7 
18. Budak K, Khater TT, Friedman NJ, et al. Corneal topographic changes induced by excision of perilimbal lesions. Ophthalmic Surg Lasers. 1999 Jun; 30(6): 458-64.

19. Yousuf M. Role of pterygium excision in pterygium induced astigmatism. JK-Practitioner 2005;12: 91-2.

20. Oh JY, Wee WR. The effect of pterygium surgery on contrast sensitivity and corneal topographic changes. Clin Ophthalmol. 2010 Apr 26; 4:315-9.

21. Archana Malik, Sudesh K Arya, SunandanSood, SoniyaBhalaSarda, Subina Narang. Effect of pterygium on contrast sensitivity. International Ophthalmology 08/2013;

22. Lin S, Reiter K, Dreher AW, et al. The effect of pterygia on contrast sensitivity and glare disability. Am J Ophthalmol. 1989 Apr 15;107(4):407-10.

23. Applegate RA, Hilmantel G, Howland HC, TuEY, Starck T, Zayac EJ. Corneal first surface optical aberrations and visual performance. J Refract Surg. 2000 Sep-Oct;16(5):507-14.

24. Pesudovs K, Figueiredo FC. Corneal first surface wavefront aberrations before and after pterygium surgery. J Refract Surg. 2006 Nov;22(9):921-5.

25. Gumus K, Topaktas D, Göktaş A, Karakucuk S, Oner A, Mirza GE. The change in ocular higher order aberrations after pterygium excision with conjunctival autograft: a 1-year prospective clinical trial.Cornea. 2012 Dec;31(12):1428-31. doi:10.1097/ICO. 0b013e 3182431465.

26. Kwon SM, Lee DJ, Jeung WJ, Park WC. Power vector and aberrations using corneal topographer and wave front aberrometer before and after pterygium surgery. J Korean Ophthalmol Soc. 2008; 49: 1737-45.

27. Applegate RA, Hilmantel G, Howland HC, TuEY, Starck T, Zayac EJ. Corneal first surface optical aberrations and visual performance. J RefractSurg. 2000 Sep-Oct;16(5):507-14.

28. Lin S, Reiter K, Dreher AW, et al. The effect of pterygia on contrast sensitivity and glare disability. Am J Ophthalmol. 1989 Apr 15;107(4):407-10.

29. Oh JY, Wee WR. The effect of pterygium surgery on contrast sensitivity and corneal topographic changes. Clin Ophthalmol. 2010 Apr 26;4:315-9.

30. Yousuf M. Role of pterygium excision inpterygiuminduced astigmatism. JK-Practitioner 2005; 12: $91-2$

31. Razmjoo H, Vaezi MH, Peyman A, et al. The effect of pterygium surgery on wavefront analysis. Adv Biomed Res. 2014 Sep 23; 3:196. doi: 10.4103/22779175.140677. eCollection 2014.

\section{How to cite this article?}

Vohra M, Agarwal R, Vohra J, Maggoo A, Rohatgi S. Effect of pterygium severity on visual acuity and contrast sensitivity. Trop J Ophthalmol Otolaryngol.2019;4(1):42-47.doi:10.17511/jooo.2019.i01.09 